\title{
POTENCIALIDADES DE LA IGLESIA DE HUAMÁN COMO ELEMENTO ESTRUCTURADOR DEL FORTALECIMIENTO DE LA IDENTIDAD LOCAL ${ }^{[*}$ POTENTIALITIES OF THE HUAMÁN CHURCH AS A STRUCTURINGELEMENT OF THE STRENGTHENING OF LOCAL IDENTITY
}

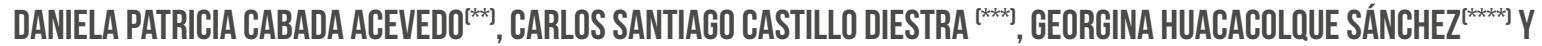 \\ JULIO MANUEL RAMÍREZ LLORCA ${ }^{[\star \star \star \star \star]}$ \\ iD https://orcid.org/0000-0001-5436-5054 \\ dcabadaac@hotmail.com \\ Universidad César Vallejo (Perú) \\ (D) https://orcid.org/0000-0001-8661-7834 \\ Ighuacacolque@gmail.com \\ Universidad César Vallejo (Perú) \\ (iD https://orcid.org/0000-0001-8231-182X \\ karloscastillo@hotmail.com \\ Universidad César Vallejo (Perú) \\ (D) https://orcid.org/0000-0002-0857-6050 \\ jrllorca@hotmail.com \\ Universidad César Vallejo (Perú)
}

\begin{abstract}
Fecha de recepción: 3 de diciembre de 2018
RESUMEN

Fecha de aprobación: 11 de agosto de 2019

En este artículo se analizan las potencialidades que posee la iglesia de Huamán como elemento estructurador de la identidad local, puesto que mediante la apropiación social del patrimonio una pluralidad de individuos se reconoce como perteneciente a un mismo pueblo y territorio. Así, se fortalece la identidad y se genera un sentido de pertenencia; por tanto, la apropiación social del patrimonio también puede ser entendida como el fundamento que permite construir la unidad en la diversidad y, por ende, el generador de nuevas identidades. El 89,8 \% de la población considera que la iglesia de Huamán presenta una suma de potencialidades, tanto históricas como patrimoniales y arquitectónicas, que le permiten convertirse en un eje estructurador de la identidad local y la memoria colectiva del distrito. Esta iglesia congrega muchas personas, no solo por la parte religiosa, sino por la diversidad de actividades que allí se producen; estas potencialidades hacen que la misma sea un elemento dinámico y catalizador de la identidad local del distrito. De esta manera, la identidad es el viejo territorio del patrimonio. Entre los objetivos reconocidos por la mayor parte de actuaciones patrimoniales que se realizan en estos ámbitos, está la construcción de las identidades locales como la autodefinición de un nosotros.
\end{abstract}

\section{PALABRAS CLAVE}

Iglesia de Huamán; identidad local; patrimonio monumental

\begin{abstract}
In this article there are analyzed the potentials that there possesses the church Huaman as structuring element of the local identity, since by means of the social appropriation of the heritage a plurality of individuals is recognized like belonging to the same village and to the same territory. This way the identity fortifies and a sense of belonging is generated; therefore, the social appropriation of the heritage also can be understood as the foundation that allows to construct the unit in the diversity and, therefore, generator of new identities. The $89,8 \%$ of the population thinks that the Church Huaman presents a sum of potentials, both historical and patrimonial and architectural that allow it to turn into an structuring axis of the local identity and the collective memory of the district. The church congregates many persons, not only on the religious part, but for the diversity of activities that there take place; these potentials do that the same one is a dynamic element and catalyst of the local identity of the district. The identity is the old territory of the heritage, between the aims recognized by most of patrimonial actions that are realized in these areas, this construction of the local identities, as autodefinition of one we.
\end{abstract}

\section{KEYWORDS}

Church of Huamán; local identity; monumental heritage

(*) Este artículo se desarrolló con base en la investigación final desarrollada en el ciclo 2018-1 del curso Patrimonio y Arquitectura, dirigido por el Dr. Arq. José Hayakawa en el Doctorado en Arquitectura de la Universidad César Vallejo (UCV).

(**) Arquitecta y máster en Arquitectura por la UCV. Actualmente cursa el Doctorado en Arquitectura en la UCV. Es docente de la Facultad de Arquitectura de UCV de Trujillo.

${ }^{(* * *}$ ) Arquitecto por la Universidad Antenor Orrego (UPAO) y máster en Arquitectura por la UCV. Actualmente, cursa el Doctorado en Arquitectura en la UCV. Es docente de la Facultad de Arquitectura de la UCV.

$\left.{ }^{(* * * *}\right)$ Arquitecta y máster en Arquitectura por la UCV. Actualmente, cursa el Doctorado en Arquitectura en la UCV. Es docente de la Facultad de Arquitectura de la UCV de Trujillo.

(*****) Arquitecto por la UPAO y máster en Arquitectura por la UCV. Actualmente, cursa el Doctorado en Arquitectura en la UCV. Es docente de la Facultad de Arquitectura de la UCV de Trujillo. 


\section{Introducción}

El patrimonio histórico representa una parte esencial del patrimonio universal, es la referencia del pasado, es lo que se transmite a las futuras generaciones, su punto de referencia. Entonces, una arquitectura transcendental para la sociedad se convierte en patrimonio, en el que no solo se incluyen edificios y monumentos, sino también documentos, trabajos artísticos, culturales, sociales y ecológicos, los cuales hacen parte del patrimonio cultural de cada pueblo. Según García (1999, p. 17), el patrimonio cultural expresa la solidaridad que une a quienes comparten un conjunto de bienes y prácticas que los identifica, pero suele ser también un lugar de complicidad social. Las actividades destinadas a definirlo, preservarlo y difundirlo, amparadas por el prestigio histórico y simbólico de los bienes patrimoniales, incurren casi siempre en cierta simulación al pretender que la sociedad no está dividida en clases, etnias y grupos, o al menos que la grandiosidad y el respeto acumulados por estos bienes trascienden esas fracturas sociales.

En ese sentido, la religión juega un papel decisivo puesto que se constituye en un elemento que permite vislumbrar el origen de la identidad. El hecho de que la identidad se conformase, tanto en Perú como en el departamento de La Libertad, a partir del catolicismo, permite que la Iglesia católica cumpla un papel clave en su desarrollo. Entonces, el disfrutar de una libertad cultural implica que los individuos se identifiquen a sí mismos como ciudadanos de un Estado, de una región, de una comunidad, pero también como miembros de grupos étnicos, religiosos y culturales. Debe entenderse esta libertad como un factor de desarrollo que supone retomar la cultura como valor humano, lo que simboliza tanto un derecho como un respeto por la cultura.

El patrimonio religioso, por su parte, desempeña un papel esencial en la identidad de muchos millones de personas, proporcionando no solo un sistema de creencias, sino también un sentimiento de pertenencia. Además, puede estimular la acción social, ya que recuerda las responsabilidades que se tienen más allá de cada persona. El patrimonio cultural —y religioso, por extensión - es fuente de identidad cultural, geográfica, religiosa, local o nacional. Todo santuario ejerce una influencia en un área geográfica determinada (Christian, 1978, p. 54; Prat i Carós, 1989, p. 217).

La importancia que reviste la iglesia de Huamán, ubicada en el antiguo caserío del mismo nombre en el actual distrito de Víctor Larco, es que posee el único estilo barroco mestizo del norte peruano, pues fue una construcción hecha para la población indígena en el siglo XVI. Este templo está delimitado exteriormente por un muro pretil, su fachada de un solo cuerpo exhibe cuatro columnas adosadas, un portón con arco de medio punto y un doble frontón triangular flanqueado por dos torres campanario; es de una sola nave y su cubierta es de par y nudillo.

Es fundamental, igualmente, para comprender cómo ha sido el devenir de la religión católica, cómo han persistido las formas de orden y la organización comunitaria en el ejercicio de la fe, de qué manera se definen los vínculos de identidad a partir de la memoria y el patrimonio cultural religioso, las distintas formas de organización comunitaria de la fe y los parentescos de diferenciación que revelan la identificación de la persona, la transmisión cultural de generación en generación y la construcción narrativa de los bienes culturales del patrimonio que fundamentan la tradición en cuanto a memoria e identidad. Entonces, cabría hacerse la pregunta: ¿cuáles son las potencialidades de la iglesia de Huamán como elemento estructurador del fortalecimiento de la identidad local?

\section{Objetivo y método}

El objetivo principal de esta investigación es analizar las potencialidades de la iglesia de Huamán como elemento estructurador de la identidad local. 
Para ello, el diseño metodológico se ha desarrollado sobre la base de entrevistas a expertos en el tema patrimonial, y a una encuesta a la población local conformada por residentes, asistentes, visitantes, fieles, devotos, etc., que con frecuencia asisten a la iglesia de Huamán. En total, fueron 196 las personas a las que se les hizo la consulta del caso.

Los datos se han procesado de acuerdo con el objetivo propuesto de la investigación. Se han tenido, asimismo, ciertas consideraciones éticas durante el desarrollo del presente artículo.

\section{Patrimonio cultural}

El patrimonio construido es un producto cultural que solo cobra real validez cuando es reconocido como tal por la comunidad, dentro de la cual se debe desarrollar el concepto de propiedad colectiva del mismo como paso inicial para asumir su real custodia. El pasado constituye para el patrimonio una instancia indispensable para el logro y mantenimiento del equilibrio de la identidad y el autorreconocimiento del hombre, puesto que es en el pasado donde se debe reconocer el especial valor que dicho patrimonio tiene en su conjunto como testimonio de una historia común (Gómez, 2009, p. 57).

La historia ha dejado un gran número de diferentes lugares de culto, a menudo con una arquitectura y unos elementos de artes plásticas de una calidad excelente. Las iglesias, los templos y otros lugares de culto son testimonios de una historia común y muestran corrientes artísticas, arquitectónicas y sociales que trascienden las fronteras de hoy en día. Además, son recursos económicos, sociales y culturales de valor incalculable que necesitan ser conservados, utilizados e interpretados en beneficio de las comunidades locales y también de la sociedad en sentido general. La religión ha dejado y deja huella en la historia de la humanidad, la cultura, la sociedad y el paisaje. Ya sea que se trate de un santuario o de una imagen, ya sea de una fiesta o de una peregrinación, o quizá las creencias y sentimientos de la gente. Lo físico, lo cultural y lo afectivo se ven influenciados por su presencia. Así, monumentos y devociones son parte del patrimonio cultural, tangible o inmaterial (Marcos, 2005, p. 36).

Al hablar de patrimonio, se encuentra también una relación directa con la herencia, la memoria y la identidad. Así, el patrimonio está íntimamente ligado con el pasado como herencia, pero es actualizado en el presente y es un referente indiscutible para el futuro; al tiempo que constituye parte importante de los rasgos de identidad. El patrimonio se transmite de generación en generación $y$, al ser la base sobre la que se cimienta la cultura, forma parte tanto de la colectividad de una sociedad como de quienes la conforman individualmente. La herencia colectiva, que se forma de la herencia del conjunto de individuos, se convierte en patrimonio gracias al tiempo, su utilidad y expresividad.

El patrimonio remite a una realidad icónica, simbólica y colectiva, porque el patrimonio cultural de una sociedad está constituido por el conjunto de bienes materiales, sociales e ideacionales que se transmiten de una generación a otra e identifican a los individuos en relación contrastiva con otras realidades sociales. Los bienes culturales forman parte de la identidad y son expresiones relevantes de la cultura de un grupo humano. El patrimonio, lo que cada grupo humano selecciona de su tradición, se expresa en la identidad. El patrimonio cultural de una sociedad lo constituyen las formas de vidas materiales e inmateriales, pretéritas o presentes, que poseen un valor relevante y son significativas culturalmente para quienes las usan y las han creado (Marcos, 2005, p. 929).

El patrimonio cultural está integrado, por consiguiente, por bienes mediante los que se expresa la identidad. Es decir, los bienes culturales a los que los individuos y la sociedad en su conjunto otorgan una especial importancia. El patrimonio es una construcción ideológica, social y cultural. El patrimonio son las formas de vida que expre- 
san la identidad de los grupos humanos. Y la identidad consiste en la interiorización por un grupo dado que posee formas de vida específicas. La identidad, entonces, se construye a partir de la alteridad, en el contraste cultural. Patrimonio e identidad son reflexiones sobre el pasado y la realidad presente. Ahora bien, como construcciones históricas, sociales y culturales, las nociones de patrimonio e identidad se revisan en cada momento histórico. Es decir, en los diferentes periodos la valoración que se hace de uno y el otro el concepto cambia significativamente.

La identidad, por otra parte, es resultado de un hecho objetivo (el determinante geográfico-espacial, los datos históricos, las específicas condiciones socioeconómicas, etc.) y una construcción de naturaleza subjetiva (la dimensión metafísica de los sentimientos y los afectos, la propia experiencia vivencial, la conciencia de pertenencia a un universo local o de otro nivel de integración sociocultural, la tradición, el capital cultural y la específica topografía mental que representan rituales, símbolos y valores). El patrimonio cumple una función identificadora porque, cuando se habla de patrimonio, se refiere a representaciones y símbolos.

Del carácter simbólico del patrimonio deriva su capacidad para representar una determinada identidad. El patrimonio, de hecho, no consiste en otra cosa que en la selección de los elementos y las manifestaciones más representativas de la realidad cultural de cada grupo social. Ahora bien, por su carácter simbólico y de significación de identidad étnica, como resultado de un proceso histórico y de una particular experiencia vivencial, puede darse una instrumentalización política del patrimonio. La identidad es una construcción social que se fundamenta en la diferencia, en los procesos de alteridad o de diferenciación simbólica. Y la imagen de la identidad se conforma desde la percepción interior y de la visión exterior. Por una parte, está el cómo se ve cada uno, y por otra, el cómo se percibe.

La identidad refiere un sistema cultural de referencia y apunta a un sentimiento de pertenencia. Es decir, la identidad se fundamenta en una construcción real y en una ideológica, que jerarquiza y fetichiza unos símbolos supuestamente propios, mediante los que se canalizan, cíclicamente, las energías y los sentimientos colectivos; porque los procesos de construcción de las identidades son, como observara Pujadas (1993), procesos ideológicos, políticos y culturales, que representan el vínculo genealógico y la herencia cultural (p. 120).

\section{Identidad local}

El estudio de identidad local refleja la vida de la comunidad, su historia, patrimonio y territorio. Su preservación ayuda a reconstruir comunidades desmembradas, a restablecer su identidad, a crear un vínculo con su pasado y a crear un vínculo entre el pasado, el presente y el futuro (Arroyo, 2001, p. 71). La identidad es el viejo territorio del patrimonio y no es de extrañar que entre los objetivos reconocidos por la mayor parte de actuaciones patrimoniales que se realizan en estos ámbitos, figure la reconstrucción de las identidades locales como autodefinición de un nosotros. Esta recreación o potenciación identitaria no solo puede revivir, volver a poblar áreas rurales, despertar interés en una población apática o lograr cohesión social, sino que, además, puede desencadenar actividades económicas y, con ello, mejorar los ingresos y la calidad de vida de la colectividad (Connor, 1997, p. 87).

Ruíz (2001) menciona que la identidad local, entendida como los elementos que definen las particularidades y la esencia de una comunidad frente a otras, generada a través del devenir histórico-social compartido, puede ser tanto un obstáculo como un facilitador de los procesos del desarrollo local (p. 15). Estos procesos implican impactos en la identidad de quienes habitan el territorio donde se realizan. Al reconocer las particularidades de una comunidad, se pueden conjugar las fortalezas y aspiraciones que subyacen a sus acciones, lo cual facilita la participación comunitaria y apela al 
sentido de pertenencia. Si no se reconoce la importancia de la identidad local en el proceso de desarrollo, se generan fracturas o exclusiones provocadas por una mirada sesgada y particular sobre el futuro de la comunidad.

\section{Las actividades a través de las tradiciones en el proceso del desarrollo de la identidad}

Las ciudades y su arquitectura constituyen la memoria construida de una sociedad. En las calles y en los muros de las urbes, se van acumulando los estratos del pasado, creando la obra colectiva más elocuente para expresar la historia y las transformaciones de la civilización. Pero la arquitectura y los espacios urbanos son también el escenario del presente, que se usa para desarrollar la vida y el espacio futuro que se quiere crear, para disfrutarlo y legarlo a las generaciones venideras. Una ciudad que intente ser solo una expresión del pasado dejará de ser una realidad urbana viva y se convertirá en un museo o en un parque temático. De esta forma, una ciudad viva y una arquitectura viva son las que reutilizan los elementos del pasado y a la vez construyen el presente e innovan el futuro. Toda ciudad y toda arquitectura han de transformarse para poder acoger las funciones actuales, para servir a la vida de hoy, y así seguir siendo útil y conservarse adecuadamente (Muñoz, 2010, p. 14).

Es por ello que, en el desarrollo urbano, se plantea la necesidad de promover una auténtica cultura, enraizada en la realidad y la cultura, juntamente con la preservación y el fortalecimiento de sus valores propios, de su identidad y autenticidad dentro del ámbito local y nacional. La cultura proporciona identidad y ayuda a forjar el carácter, lo cual otorga un sentido de pertenencia y una sensación de seguridad en la comunidad. Por tanto, no es un eje más del desarrollo, sino el eje de referencia que concatena, da unidad y dinamismo al resto de las dimensiones, lo que significa que no puede existir un desarrollo que satisfaga las necesidades cada vez más crecientes de los miembros de la comunidad si este no utiliza la cultura como base para la consolidación de los modos de vida, los derechos fundamentales del ser humano, los sistemas de valores, las tradiciones y las creencias.

Si se concuerda en que los individuos y los grupos intervienen en la vida comunitaria cuando se identifican con la comunidad, cuando tienen el conocimiento y la significación emocional y afectiva de que pertenecen a esa comunidad, parece oportuno detenerse ahora a reflexionar sobre la relación entre los conceptos de identidad y pertenencia. Los miembros de la comunidad que se identifican afectivamente como grupo otorgan un valor positivo al hecho de ser de una localidad atractiva, interesante, acogedora, segura y con una continuidad histórica. Se encuentran identificados por y con la misma cultura, es un elemento de cohesión, de unión: las personas encuentran en su medio local una base de seguridad y confianza, un motivo de orgullo individual y colectivo.

En la actualidad, y luego de largos procesos de reflexión, en el ámbito científico y cultural, se ha creado conciencia de la importancia del patrimonio religioso, no solo desde el punto de vista de la devoción, sino como un foco de desarrollo local, principalmente, debido al turismo y todas las actividades comerciales derivadas que esto implica. Pequeñas comunidades rurales, poseedoras de verdaderas joyas arquitectónicas, se han transformado en foco de atracción turística, tanto por el valor en sí mismo que tienen los templos, como también por las festividades que atraen a fieles y laicos. De esta manera, las comunidades han comprendido la importancia de conservar su patrimonio como parte importante del desarrollo social y económico.

\section{La religión como identidad colectiva}

Al examinar el repertorio de identidades colectivas mantenidas por los individuos, se puede apreciar que existe un límite para la pertenencia, más allá del cual el mundo social existente no es considerado como propio. Aunque esta identidad colectiva 
límite no tenga una expresión sensible en ciertos momentos, alcanzará su significación cuando el conjunto de individuos que se incluye dentro de él entra en relación de proximidad con individuos o grupos exteriores a ese límite. El conjunto de individuos que está dentro entra en relación de alteridad con los de fuera, con lo cual la identidad colectiva de los de dentro cobra sentido; sentido inexistente sin esa alteridad. La religión como expresión cultural de un pueblo, etnia o grupo de personas, constituye uno de los pilares fundamentales de la cultura, ya que sustenta un conjunto de creencias, ideologías, percepciones del mundo y simbolismos que son reconocidos claramente por los miembros que constituyen una determinada estructura de unión espiritual e intelectual.

La Iglesia, en este sentido, ha jugado el inapreciable papel de memoria con la conservación y ordenación del patrimonio cultural, puesto que ha sido depositaria de gran parte de los valores y conocimientos — sabiduría, en suma - de la antigüedad, acervo que supo conservar, acrecentar, enriquecer y transmitir con generosidad y genio a lo largo de los prolongados siglos oscuros. Por otro lado, la Iglesia sirve para asegurar su función evangelizadora (además de cultural y, eventualmente, civilizadora) en el presente y en el futuro. Para Durkheim (1967), en la religión se encuentra la forma primera de ese espíritu común que hace que la sociedad se mantenga unida en su conjunto (p. 4). La sociedad es un conjunto de ideas, de creencias, de sentimientos de todos los tipos que se desarrolla por los individuos. Estudiar la religión es, por tanto, remontarse a las fuentes del vínculo social para poder pensar mejor la refundación posible de este vínculo en una sociedad que ha llegado a ser laica.

En general, se puede decir que la identidad colectiva religiosa se manifiesta en forma activa también en aquellas realidades sociales en las que conviven diferentes confesiones religiosas. La diversidad religiosa presente en una sociedad puede dar lugar a diferentes formas de convivencia. Un factor fundamental que define la forma de la coexistencia es la posible jerarquización social de las diferentes confesiones, tal como sucede con los países en los que una determinada confesión es la que ha sido históricamente la de referencia y a los que, con posterioridad a esa homogeneidad, van llegando flujos de población extranjera portadora de creencias religiosas diferentes. Este es el caso de las sociedades europeas occidentales en la época contemporánea, en la que las dos leyes enunciadas por Tilly (1990) para la modernización de estas sociedades comienzan a difuminarse (Pérez, 2016, p. 11).

\section{Identidad y patrimonio cultural}

El patrimonio cultural es el producto de un proceso que se realiza como comunidad de valoración, conservación y promoción de determinadas entidades materiales e inmateriales que, en conjunto, se considera que debe tener un valor diferente. Así, el patrimonio cultural se transforma en manifestación concreta del bien común para la comunidad y la identidad gira en torno a él. Por esto, el patrimonio cultural es esencialmente un ente social. No es aquel que se preocupa de la conservación de los «bienes muertos» de la cultura, sino el que busca relacionarse desde la identidad y lo que cada uno es, con lo heredado y que ha constituido su comunidad. El patrimonio cultural tiene, por lo tanto, una clara relación con las necesidades de la población, porque adquiere su pleno sentido en la medida en que tiene una relación próxima y real con cada persona.

El patrimonio así entendido está estrechamente ligado a la memoria colectiva y, por ende, a la construcción de la identidad de un grupo o de una sociedad. En efecto, el proceso de patrimonialización responde en primer término a una «demanda social de memoria» en búsqueda de los orígenes y de la continuidad en el tiempo, lo que conduce a un gigantesco esfuerzo de inventario, de conservación y de valorización de vestigios, reliquias, monumentos y expresiones culturales del pasado. Y como la memoria es gene- 
radora y nutriente de identidad, responde también a la necesidad de crear o mantener una identidad colectiva mediante la escenificación del pasado en el presente.

Algunos enfoques contemporáneos sobre el concepto de patrimonio cultural hacen hincapié en la idea de construcción social y en el papel del patrimonio como el referente simbólico de la identidad cultural. La idea de construcción social, tal como se presenta, se refiere al patrimonio como algo que no existe en la naturaleza, que no ha existido en todos los periodos históricos o en todos los contextos socioculturales. Como herramienta del sistema simbólico estatal, la selección de un objeto dentro un listado potencialmente amplio implica una operación intelectual que se propone hegemonizar el discurso identitario (Prats, 2004, p. 15). De esta manera, los objetos elevados a la categoría de patrimonio cultural sintetizan un proyecto identitario, que pone en juego todas las instituciones del Estado con el fin de llevar a cabo un proceso forzoso de integración con la intención de homogeneizar la población en una cultura nacional.

El patrimonio cultural representa un conjunto de elementos naturales, históricos, materiales e inmateriales de gran valor para la sociedad. Se trata, por tanto, de un bien colectivo que forma parte de la personalidad cultural e identidad del patrimonio, es decir, un bien colectivo sedimentado de elementos diversos e imbricados que forman un todo, producto de la convivencia de pueblos y culturas diversas sobre un mismo solar a lo largo de la historia. Ello obliga a planificar las políticas de conservación y protección de bienes culturales en relación con la gestión integral del territorio, sea una región o un municipio, de forma que cuando se habla de desarrollar un territorio con infraestructuras de comunicación, educativas, sociales o sanitarias, también deben incluirse los bienes culturales, pues forman parte igualmente de la calidad de vida y de los recursos económicos de los habitantes de la zona.

\section{La iglesia de Huamán como elemento estructurador}

\section{La iglesia y su evolución histórica-arquitectónica}

Correa (2005) menciona que, bajo el pretexto de la evangelización por parte de la conquista, se dispuso que los indios dispersos en sus campos agrícolas se agruparan en pueblos (p. 52). Es así que el emplazamiento de Trujillo se determinó debido al correcto aprovechamiento de las acequias prehispánicas y al ya existente asiento de Mansiche, así como la cercanía del pueblo de Santiago de Huamán y los pueblos de Santa Lucía de Moche y el puerto y pueblo de Huanchaco y, más lejos, camino a la sierra, el pueblo de San Juan Bautista de Simbal.

La iglesia de Huamán se encuentra en la plaza principal de Huamán, en el actual distrito de Víctor Larco, en la parte suroeste de la provincia de Trujillo. Asimismo, su antigüedad data del siglo XVI, perteneciente al antiguo cacicazgo de Huamán. En la actualidad, de este antiguo pueblo indígena solo queda la plaza y la iglesia. Este templo fue destinado a la evangelización de los pueblos indios que trabajaban en las haciendas de españoles y se destaca su fachada de estilo barroco mestizo con pinturas murales policromadas.

Su edificación en un principio fue lenta y modesta. Inicialmente, fueron iglesias costeadas por los encomenderos y también por personas piadosas que quisieron manifestar su fe y agradecimiento. A lo largo de los años, estas iglesias sufrieron los rigores que el clima les impuso, $y$, así, terremotos y aluviones se unieron a la fragilidad de los materiales usados en su construcción para causarles daños, por lo que luego fueron reparadas, pero con los consiguientes cambios en su estilo y, principalmente, en los materiales utilizados en la cobertura de estos templos, que en muchos casos fue una nueva equivocación (ver Figuras 1 y 2). 


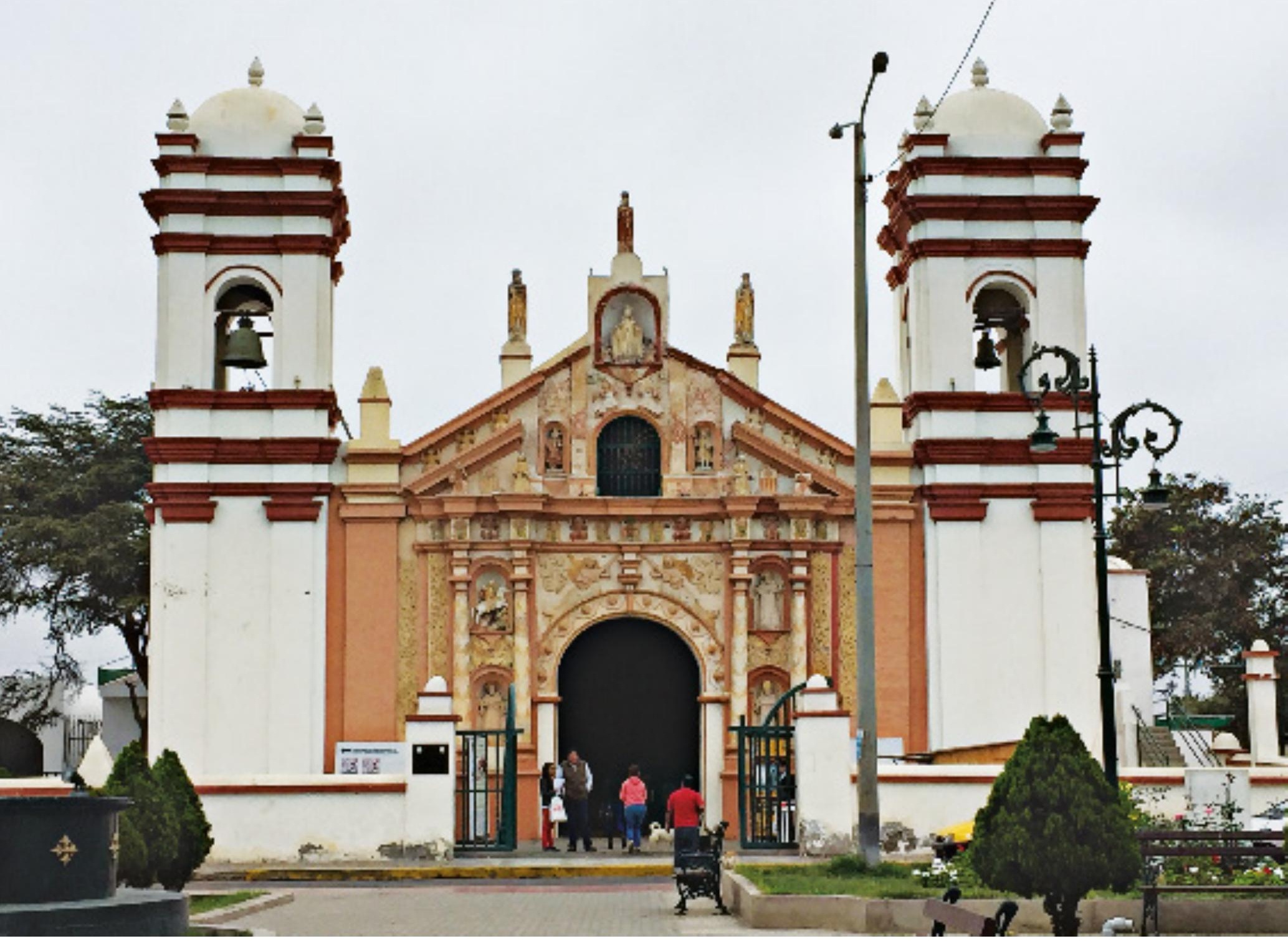

Figura 1. Actual iglesia de Huamán. Archivo fotográfico de los autores, 2019
La iglesia de Huamán no ha experimentado a través de los siglos mayores modificaciones, y pertenece al extenso grupo de iglesias o parroquias de indios de la etapa colonial que se extendió por todo el Perú: el tipo de nave alargada, algunas veces con ábside ochavado, muros de adobe y cubierta de madera de par y nudillo. Un arco triunfal separaba la estrecha y alargada nave del presbiterio, cuya altura era mayor, produciendo la característica silueta lateral de techo quebrado que aún puede verse en la sierra y el Altiplano. El cambio de gustos y los sismos que han azotado las cubiertas de madera son responsables de que pocas de estas iglesias de la costa se puedan encontrar conservando su forma y estructura originales.

En cuanto a la cúpula, su trazo y proporciones no concuerdan en absoluto ni con la planta rectangular del espacio interior que cubre, ni con la volumetría exterior. Es de quincha, estructurada en gran parte con madera aserrada y en el interior se han improvisado unas pechinas para disimular la desadaptación (ver Figura 3).

La portada de Huamán es estilísticamente heredera del mestizo cajamarquino. Así lo indica la disposición general y las características de la ornamentación: los santos en las hornacinas y los ángeles en San Antonio y Belén de Cajamarca, que son sustituidos por las sirenas de Huamán. El segundo cuerpo de San Antonio y Belén, con sus esculturas únicas, se hallan representadas en Huamán con idénticos elementos. La hornacina superior, fuera del conjunto arquitectónico, repite lo que existe en la ciudad de la sierra. Por supuesto que al no ser abundante la piedra, todos los alto relieves de la decoración de Huamán son de argamasa de cal, yeso y arena, sobre el muro de soporte de estructura mixta de adobe y ladrillo, siendo de este último las columnas y molduraciones. Debajo 


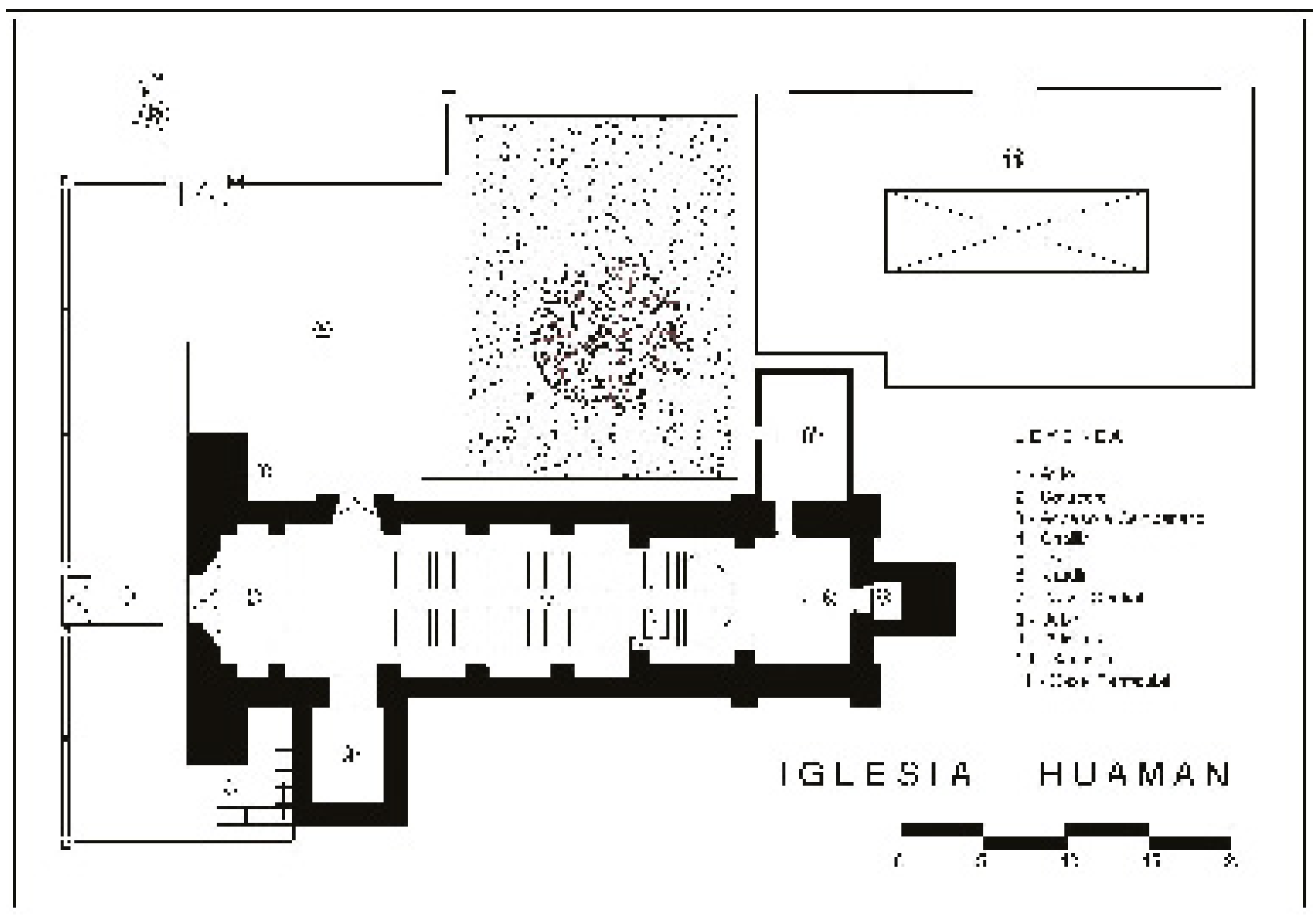

de la pintura reciente, que presenta en blanco, el orden y relieves sobre fondo celeste, subsiste la rica policromía original, que, además del blanco y negro, combina los colores tradicionales rojo almagre, amarillo oropimente y azul añil. La iglesia de Huamán, con la decoración de su gran portal, es el único ejemplo de estilo mestizo religioso en la costa peruana, pues conjuga elementos indígenas e hispánicos, de manera que representa una de las más hermosas obras de la arquitectura virreinal. En esta iglesia, se halla la persistencia del arcaísmo como elemento formal y previo hacia el arte mestizo del siglo XVIII y, además, es la más bella joya del arte indígena de su época, entroncado en las orillas del Pacífico con las estructuras y modelos hispánicos (ver Figura 4, 5 y 6).

\section{Significado cultural e identitario de la iglesia de Huamán}

La experiencia religiosa, en tanto forma de ser y estar en el mundo, ha construido sus propias formas simbólicas para transmitir, presentar y representar las dimensiones sensibles y no sensibles de su fe. La eficacia simbólica del patrimonio cultural depende en gran parte del grado de consenso y de representación que alcance la entidad significante-significado, así como también del nivel de contextualización que logren los referentes significativos mediante prácticas, discursos y dispositivos comunicativos que conduzcan a su actualización y resignificación. Por tanto, objetos, lugares, ritos y sujetos colectivos constituyen una síntesis, un todo inseparable, que hacen posible la reproducción de los universos simbólicos legitimados socialmente al interior de un sistema cultural, contribuyendo de ese modo al sentido de pertenencia y de cohesión del grupo, en su necesario e inevitable proceso de cambio (Seguel, et al., 2010, p. 47).
Figura 2. Plano de iglesia de Huamán. Elaboración propia, 2019.

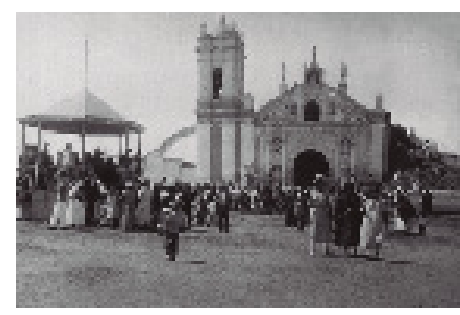

Figura 3. Iglesia de Huamán (1925). En Vega, M, 2009. 
devenir Vol.6, N¹2, JULIO-DICIEMBRE 2019, PP. 137-154 - EstudIOS I ISSN 2312-7562 | E-ISSN 2616-4949

UNIVERSIDAD NACIONAL DE INGENIERÍ, LIMA

doi: https://doi.org/10.21754/devenir.v6i12.747

Figura 4. Iglesia de Huamán (1925). En Vega, M, 2009.

Figura 5. Iglesia de Huamán (1925). En Vega, M, 2009.

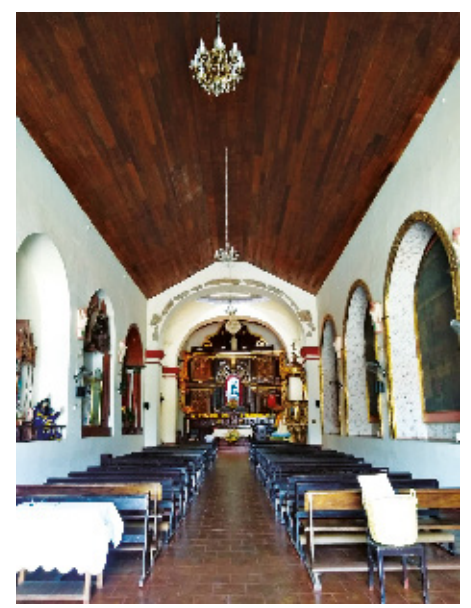

Figura 6. Vista actual del interior de la iglesia Huamán. Archivo fotográfico de los autores, 2019.
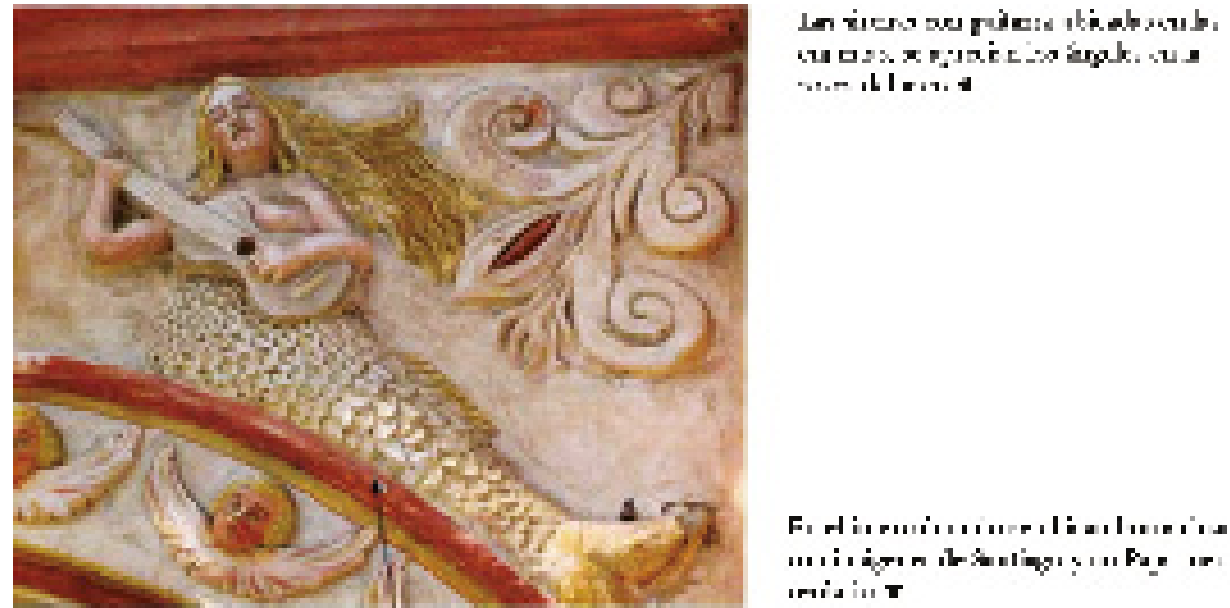

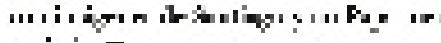
II I III T

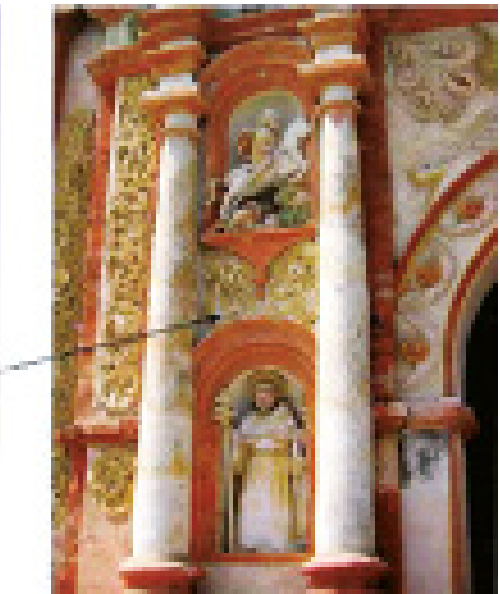

El patrimonio religioso reviste un carácter especial, ya que constituye la síntesis de referentes significativos y simbólicos que se actualizan y reconstruyen durante las prácticas devocionales. Es el elemento central de los rituales religiosos, y forma parte activa de fiestas, peregrinaciones y procesiones. Son los objetos y lugares en los cuales los creyentes expresan su fe, sus miedos y alegrías, sus deseos y sueños, a través de oraciones, plegarias, mandas y promesas. Tiene un papel de vital importancia en la transmisión, expresión y sostenimiento de la fe, y otorga identidad espiritual, significado y sentido a la existencia de aquellos fieles que le profesan su amor y devoción. Toda intervención sobre el trinomio materia-forma-contenido implica una intervención en la dimensión signo-símbolo, en la síntesis imagen-sujeto-sagrado, y, en consecuencia, en el sustrato, en la presencia, en la representación misma de la divinidad y la fe.

En términos generales, se pude afirmar que la iglesia de Huamán se encuentra profundamente arraigada en la historia e imaginario colectivo del distrito de Víctor Larco. Su patrimonio religioso contiene signos cualificados de la historia espiritual, vienen a ser estos los que muestran la vida entregada y comprometida de muchas personas, siendo expresión de la memoria histórica de ese pueblo, y permiten descubrir su camino de fe y esperanza, a través de obras que acompañaron a esa gente durante largo tiempo. Así, pues, el patrimonio conserva y pone en evidencia el recuerdo de una vi- 
vencia eclesial, expresada a través de diversas formas artísticas. Se puede pensar que, además, ponen en contacto con una historia que, aún en lo civil y cotidiano, con sus angustias y esfuerzos, ha estado guiada por la providencia de Dios que nunca abandona, como es leída por la gente creyente.

\section{Resultados}

La idea de apropiación social del patrimonio reclama así la participación colectiva, pues la considera eje de construcción de las identidades y, por ende, de la consolidación de un «nosotros». Mediante la apropiación social del patrimonio, una pluralidad de individuos se reconoce como perteneciente a un mismo pueblo y a un mismo territorio. Así, se fortalece la identidad y se genera un sentido de pertenencia. Este proceso engendra un «nosotros» que, a su vez, crea y recrea acervos para que cada persona se reconozca a ella misma como parte de un todo. De este modo, la apropiación social del patrimonio también puede ser entendida como el fundamento que permite construir la unidad en la diversidad y, por tanto, ser el generador de nuevas identidades. Lo anterior no se explica, sino que introduce la noción de patrimonio cultural vivo, el cual, además de incluir las creaciones materiales representadas en los monumentos históricos y los documentos escritos que nos ha legado el pasado, otorga especial atención a todas aquellas creaciones inmateriales a las cuales las mismas comunidades asignan un valor fundamental. Entre ellas, se destacan las expresiones de la vida cotidiana y espiritual, cuyas manifestaciones están en profunda relación con el fortalecimiento de la identidad, el sentido de pertenencia y las proyecciones de cada pueblo, nación o comunidad.

El edificio, en tanto templo histórico, se constituye como tal también a través de los elementos que lo albergan y embellecen; los bienes que en él habitan se solidarizan en un ejercicio de composición semántica que se traduce en la discursividad histórica del lugar. La valorización del conjunto está dada por el reconocimiento histórico-cultural para el Estado y religioso para la iglesia. La visibilidad del patrimonio religioso exhibe, por lo tanto, las contradicciones de universos semánticos divergentes que se dirimen en la arena del discurso, como las tensiones entre las ideas respecto del lugar y fines de los objetos culturales en el imaginario urbano. Las iglesias de la ciudad fueron testigos de grandes acontecimientos de nuestra historia; muchos religiosos de distintas órdenes comprometidos en la construcción de una nación y de una sociedad, dejaron infinidad de testimonios que nos hablan de nuestro pasado, de nuestra identidad, pero, fundamentalmente, son siempre formadores del presente.

El patrimonio permite la reconstrucción de la memoria histórica del sujeto social al que está asociado; aquí, explícitamente, dado por la Iglesia. Para la institución eclesiástica, los bienes patrimonializados, e incluso aquellos que no lo fueron, pero que a sus ojos gozan de un significativo valor artístico o religioso, se encuadran en una nueva concepción evangelizadora. Por ello, en la actualidad las iglesias se configuran como entidades cruciales a la hora de promover políticas culturales que entienden el patrimonio cultural local como elemento integrador y de desarrollo para los miembros de una comunidad.

Los rasgos culturales y de identidad se plasman en el patrimonio de forma esencial. No existe patrimonio cultural sin presencia humana, y este patrimonio identifica la identidad y cultura de la comunidad que lo ha creado. Esta, a su vez, puede determinar las de otras sociedades o culturas con las que esté comunicada. Así, la Iglesia establece los criterios de valoración de su patrimonio cultural de forma genérica, y define su identidad a través de las expresiones culturales de fe legadas. Con esta estructura y criterio de creación e identificación de identidades culturales, son escogidas aquellas expresiones esenciales y únicas, y se deja de lado a otras que no entran en su criterio de valoración. Por este motivo, tanto la apreciación del patrimonio cultural como de sus categorías sociales y culturales son consideraciones evolutivas y mutables. 


\section{Análisis de las potencialidades de la iglesia de Huamán como elemento estruc- turador del fortalecimiento de la identidad local}

Entre las manifestaciones, materiales como inmateriales, a las que una sociedad otorga valor y significado y que son parte de su cultura local, las mismas se convierten en su patrimonio, y la toma de conciencia de ello conforma su identidad. El patrimonio representa, por lo tanto, el conjunto de elementos o recursos presentes o recibidos de un tiempo pasado posibles de conservar en un futuro porque podrían ser utilizados. En este encuadre, se reconoce la existencia de un potencial usuario que otorga un valor y para quien ese patrimonio puede constituir un factor de identidad. Por ello, en el distrito de Víctor Larco, la iglesia de Huamán se emerge como ese patrimonio histórico, arquitectónico y monumental que encierra un sinnúmero de significados y trascendencia social para su población. En ese sentido, cuando se le preguntó a los especialistas y pobladores si estos estiman que la iglesia de Huamán es un elemento estructurador del fortalecimiento de la identidad local en Víctor Larco, se obtuvieron las siguientes respuestas:

La Figura 7 muestra que el 89,8 \% de la población encuestada, compuesta por fieles, devotos, visitantes y turistas, cree, desde su posición personal, que, efectivamente, la iglesia de Huamán presenta una suma de potencialidades, tanto históricas como patrimoniales y arquitectónicas, que le permite convertirse en un eje estructurador de la identidad local y la memoria colectiva del distrito. De la misma forma, entre los especialistas y pobladores se encontró que estos contemplan que la iglesia de Huamán es un elemento del fortalecimiento de la identidad local en Víctor Larco, puesto que esta es parte de la historia del pueblo de Huamán, porque forma parte de la evangelización del pueblo indígena. Sumado a ello, la Iglesia congrega muchas personas, no solo por la parte religiosa, sino por la diversidad de actividades que allí se producen. Estas potencialidades hacen que la misma sea un elemento dinámico y catalizador de la identidad local del distrito.

Entre las potencialidades, destacan a la iglesia de Huamán como elemento del fortalecimiento de la identidad local, se tienen las siguientes: material, que viene a ser la suma de los elementos arquitectónicos que forman parte de la edificación, incluido el mobiliario, como el púlpito, los libros, entre otros; inmaterial, como las danzas, las comidas, las costumbres, las celebraciones o las procesiones, según el Ministerio de Cultura. De la misma forma, se podría entender a la religión, las actividades festivas, las actividades propias de la iglesia y su volumetría como arquitectura del lugar.

\section{La apropiación social-urbana de la iglesia de Huamán y la identidad local}

La imagen de la ciudad no es más que la suma de creencias, ideas e impresiones, percepciones y valores que una persona o un grupo tiene de la ciudad. Es el modo como los ciudadanos la representan en su mente, después de vivir un sin número de experiencias en ella; por lo cual, la imagen no siempre expresa lo que esta es en realidad, sino como es vista y comprendida por las personas. La gestión de esta, conjuntamente con la identidad, es importante porque a través de ellas es posible explicar desde todas sus dimensiones las representaciones que los diversos habitantes hacen de un lugar. Su significado no se limita a las propiedades físicas del sitio, sino que evoca dimensiones emocionales en las personas que viven y experimentan cotidianamente el hecho urbano y social de la ciudad.

La identidad conforma no solo una mirada nostálgica al pasado, sino la huella imborrable sobre la que se funda la vida, la actividad y el porvenir de la ciudad, y, por ende, de su imagen urbana. Es desde esta perspectiva integradora que se forma el concepto de identidad social-urbana, ya que los individuos de una ciudad forman su propia identidad social con base en considerarse pertenecientes a un espacio determinado, por lo cual las personas de un lugar pueden definirse a sí mismas con una apropiación 
selectiva de un entorno urbano con valor representativo y simbólico. Para Fonseca (2005), la identidad se territorializa cuando se crea sentido del lugar, cuando los individuos desarrollan conciencia de saberse y sentirse de un lugar determinado, de modo que reconocen e identifican su pertenencia en un contexto espacial (p. 15). Esta relación entre identidad y territorio se expresa en la existente coherencia que desarrolla la identidad cultural y la identidad espacial (territorial) que el ciudadano integra en la imagen de la ciudad, que pertenece a sus habitantes y no necesariamente a toda la ciudad, porque es el modo en que los ciudadanos la representan en su mente. En este sentido, la imagen identifica la ciudad no como es, sino como es vista. Respecto de este punto, se preguntó a los especialistas y pobladores si consideraban que la apropiación social-urbana es una de las potencialidades de la iglesia de Huamán que la convierten en un elemento estructurador del fortalecimiento de la identidad local. Se obtuvo la siguiente respuesta:

La figura 8 muestra que el $76,5 \%$ de la población encuestada, compuesta por fieles, devotos, visitantes y turistas, contempla, desde su posición personal, que la apropiación social-urbana es una de las potencialidades de la iglesia de Huamán que la convierte en un elemento estructurador del fortalecimiento de la identidad local del distrito de Víctor Larco. En atención a ello, se puede afirmar que sí constituye una potencialidad, puesto que la sociedad ha convertido en suyo, apropiándose de las actividades, muebles e inmuebles según normas internacionales. Igualmente, las actividades que se realizan a su alrededor, así como las fiestas patronales, concentran gran cantidad de público sobre este volumen y su contexto inmediato, esto muestra una significativa apropiación social-urbana del contexto inmediato a la iglesia como monumento y hecho religioso.

\section{El valor monumental de la iglesia de Huamán y la identidad local}

Muchos elementos pueden ser considerados como formas simbólicas o soporte de significados culturales: los modos de comportamiento, las prácticas sociales, los usos y costumbres, el vestido, la alimentación, la vivienda, la organización del espacio y del tiempo, etc. Sin embargo, hay ciertos artefactos o manifestaciones culturales que adquieren el carácter de "sagrados», en términos de Durkheim (1982, p. 231). Es decir, gozan de un valor especial que los constituye en elementos de referencia simbólica para una cultura, en los que estos adquieren la categoría de patrimonio cultural. Un patrimonio que es fundamentalmente histórico, aunque incesantemente incrementado por las creaciones del presente, lo que le confiere un carácter procesual y dinámico, que se rearticula constantemente en función de contextos sociohistóricos específicos, en los cuales, y por medio de los cuales, se producen, transmiten y reciben tales formas simbólicas.

Bajo esta perspectiva, los patrimonios culturales se refieren a cualidades que son atribuidas a determinados bienes o manifestaciones de acuerdo con jerarquías que valorizan unas producciones y excluyen otras. Se infiere de ello que no existe lo patrimonial en sí, sino que estas son ciertas categorizaciones y calificaciones que son construidas socialmente. Este proceso social de calificación moviliza a diversos actores sociales: los productores de calificación, eruditos, agentes públicos, arquitectos, organismos especializados, etc., y los receptores y usuarios de dichas categorizaciones, los cuales muchas veces carecen de instancias especializadas de producción, transmisión y de consagración de obras. En este proceso, ambos tipos de actores pueden obrar de manera concertada, haciendo alianzas o redes, o bien pueden constituirse en actores que ponen en disputa ciertas categorizaciones culturales.

La categorización universal de los valores de ciertos patrimonios culturales ha puesto de manifiesto no solo una nueva forma de construcción social de los usos y sentidos de los bienes culturales, sino también transformaciones en las formas de apropiación y acceso igualitario a estos bienes. La reconstrucción y apropiación del patrimonio mundial en el ámbito de las comunidades específicas ha puesto de manifiesto que 
devenir Vol.6, N¹2, JULIO- DICIEMBRE 2019, PP. 137-154 - EstUDIOS I ISSN 2312-7562 | E-ISSN 2616-4949

UNIVERSIDAD NACIONAL DE INGENIERÍ, LIMA

doi: https:/ / doi.org/10.21754/devenir.v6i12.747

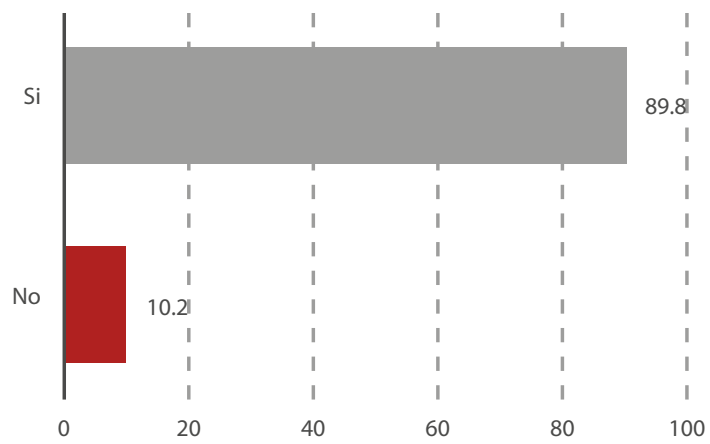

Figura 7. Valoración de las potencialidades. Elaboración propia, 2019.

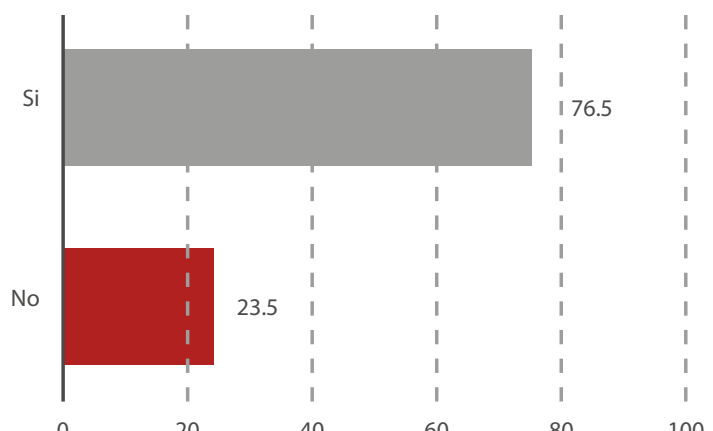

Figura 8. Apropiación social-urbana de la iglesia de Huamán. Elaboración propia, 2019.

estos se han constituido en expresiones de diversos conflictos e intereses sociales. Ello ha reconfigurando no solo el valor que los diversos grupos sociales le asignan a sus patrimonios, sino también las dinámicas sociales en torno a ellos. A través de estos procesos, se ha podido evidenciar el valor simbólico del patrimonio cultural, como expresión de una identidad y memoria colectiva y como un patrimonio vivido y compartido. Sobre el particular, se les preguntó a los especialistas y pobladores si creían que el valor monumental es una de las potencialidades de la iglesia de Huamán que la convierten en un elemento estructurador del fortalecimiento de la identidad local, se obtuvo la siguiente respuesta:

La Figura 9 muestra que el 79,6 \% de la población encuestada, compuesta por fieles, devotos, visitantes y turistas, considera, desde su posición personal, que el valor monumental es una de las potencialidades de la iglesia de Huamán que la convierten en un elemento estructurador del fortalecimiento de la identidad local del distrito de Víctor Larco. Se entiende que el valor monumental es una potencialidad porque forma parte de la historia del pueblo de Huamán, su historia es sinónimo de identidad y localidad, puesto que pertenece al mismo. Asimismo, el bien inmueble está considerado por la región y por la nación como una edificación con valor monumental según decreto supremo. En este sentido, cabe precisar que el valor monumental es una forma de rescatar la historia y, en consecuencia, la identidad de un espacio que muestra connotaciones histórico-monumentales.

\section{Actividad religiosa-cultural de la iglesia de Huamán y la identidad local}

La historia religiosa de cualquier pueblo está ligada estrechamente a una cultura, a la cual refleja siempre y que es propia de un determinado tiempo y lugar. En dicha cultura, se pone en evidencia el tejido histórico, cultural, social y religioso del territorio habitado por esa comunidad humana, incluyendo su propio devenir con los cambios culturales de la contingente caducidad. En las expresiones del patrimonio religioso, por lo tanto, se pueden leer las manifestaciones de la cultura propia de un pueblo, en su momento histórico y su acontecer.

La religión acompaña al hombre y a la sociedad como un elemento básico de la composición del individuo y de su propia identidad, de manera que las formas en que se presenta y organiza la religión al interior de la masa social son lo que le dan el carácter de una estructura y de una entidad que va a formar parte del devenir humano. Tan importante es la referencia de la religión para la sociedad que de ella depende gran parte del accionar moral que se haga presente. En buena medida, la religión también determina la forma de pensar de las sociedades, es decir, lo que se ve reflejado en el individuo, proporcionando un rasgo característico que da identidad a cada una de las 


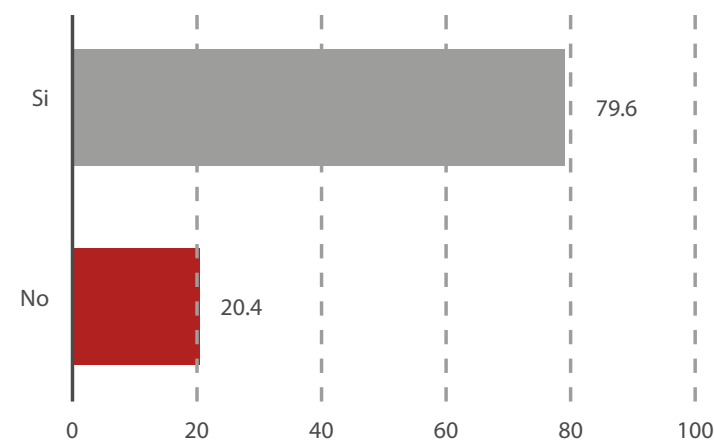

Figura 9. El valor monumental de la iglesia de Huamán. Elaboración propia, 2019.

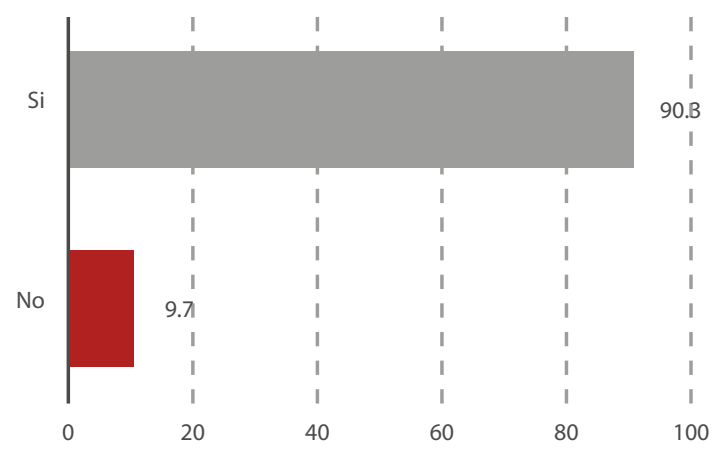

Figura 10. Actividad religiosa-cultural de la iglesia de Huamán. Elaboración propia, 2019.

formas distintas de concebir la realidad. Es entonces que, en el estudio de la relación entre las formas de expresión religiosas y la sociedad que las propicia y las mantiene, se puede lograr discernir algunas de las características innatas de dicha sociedad, ya que cada comunidad va a construir y determinar cierto tipo de comportamiento religioso muy específico, pero se van a encontrar ciertas características que les son comunes a todas las prácticas de la religión (Camarena y Tunal, 2009, p. 9).

El elemento ideológico agrupa aspectos relacionados con los valores, creencias, manifestaciones y religiosidad, sintetizándolas en un punto en común que es compartido por los diferentes públicos de la ciudad que se identifican con ella. Estos, por ende, desarrollan un sentido de pertenencia y reconocimiento hacia un concluyente lugar, así como también a las actividades que en él se desarrollan. Dentro del aspecto ideológico, es el tema religioso que tiene gran importancia para los ciudadanos, el mismo expresa, junto con lo cultural, la esencia de cada localidad, incluso cuando las ciudades son centros de culto religioso, la identidad puede configurarse en torno a este aspecto. Los valores religiosos y su importancia van más allá de una creencia colectiva, estos forjan y explican el modo de ser y hacer ciudad.

Como consecuencia de dicha relevancia de la actividad religiosa, surge el indicador del elemento ideológico, determinado por la valoración sobre la importancia de la arquitectura religiosa, está más allá de ser solo el escenario de un culto común, expresa muchas veces para los habitantes un elemento de identidad permanente valorado incluso por los no creyentes; de modo que es en este aspecto donde se encuentra la clave para la preservación de la misma, ya que ella sintetiza de modo evidente la historia, la religiosidad y la fe de un pueblo. En torno a este componente, se preguntó a los especialistas y pobladores si consideraban que las actividades religiosas-culturales son una de las potencialidades de la iglesia de Huamán que la convierten en un elemento estructurador del fortalecimiento de la identidad local. Se obtuvo como respuesta lo siguiente:

La Figura 10 muestra que el 90,3 \% de la población encuestada, compuesta por fieles, devotos, visitantes y turistas, considera, desde su posición personal, que la actividad religiosa-cultural es una de las potencialidades de la iglesia de Huamán que la convierten en un elemento estructurador del fortalecimiento de la identidad local del distrito de Víctor Larco. Además, esto se debe en parte a la formación religiosa del pueblo de Huamán, así como a las actividades que permiten reunir a una gran cantidad de personas que hacen uso de ese espacio público, juntándose las actividades religiosas, culturales y comerciales. Tal es el caso de los niños que siguen la catequesis, pues todos los domingos asisten fervientemente a las actividades programadas. Consecuentemente, las actividades religiosas y culturales son las que dan vida al monumento y sus contex- 
tos, aquellas que tejen conexiones y que vuelven dinámico el espacio social. Asimismo, generan nuevos escenarios que propician la identificación de los pobladores y visitantes, lo cual convierte a la iglesia de Huamán en un símbolo representativo no solo del distrito, sino de la ciudad.

El patrimonio cultural mantiene estrecha relación con los pueblos que los han creado, los usan y viven. El valor que representa esta riqueza cultural, tanto para estos pueblos como para el resto de la humanidad, hace necesaria una estructura de protección que asegure su pervivencia en el tiempo y la transmisión a las generaciones futuras. La iglesia ha potenciado la cultura y ella, en sí misma, es fuente de manifestaciones y expresiones culturales. Las tradiciones religiosas son también culturales $y$, aunque sean transmitidas, se hacen vivas en el seno de las sociedades y comunidades eclesiales. El patrimonio y la identidad cultural no son elementos estáticos, sino entidades sujetas a permanentes cambios; están condicionadas por factores externos y por la continua retroalimentación entre ambos. La identidad está ligada a la historia y al patrimonio cultural. La identidad cultural no existe sin la memoria, sin la capacidad de reconocer el pasado, sin elementos simbólicos o referentes que le son propios y que ayudan a construir el futuro. La identidad es el viejo territorio del patrimonio y no es de extrañar que entre los objetivos reconocidos por la mayor parte de actuaciones patrimoniales que se realizan en estos ámbitos figure la (re) construcción de las identidades locales.

\section{Conclusiones}

- Mediante la apropiación social del patrimonio, una pluralidad de individuos se reconoce como perteneciente a un mismo pueblo y territorio. Así, se fortalece la identidad y se genera un sentido de pertenencia. Por tanto, la apropiación social del patrimonio también puede ser entendida como el fundamento que permite construir la unidad en la diversidad y, en consecuencia, el generador de nuevas identidades.

- El 89,8 \% de la población encuestada considera que la iglesia de Huamán presenta una suma de potencialidades, tanto históricas como patrimoniales y arquitectónicas, que le permiten convertirse en un eje estructurador de la identidad local y la memoria colectiva del distrito. La iglesia congrega muchas personas, no solo por la parte religiosa, sino por la diversidad de actividades que allí se producen. Estas potencialidades hacen que la misma sea un elemento dinámico y catalizador de la identidad local del distrito.

- Entre las potencialidades que destacan a la iglesia de Huamán como elemento del fortalecimiento de la identidad local, se tienen las siguientes: la material, que viene a ser la suma de los elementos arquitectónicos que forman parte de la edificación, incluido el mobiliario, como el púlpito, los libros, entre otros; la inmaterial, como las danzas, las comidas, las costumbres, las celebraciones o las procesiones, según el Ministerio de Cultura. De la misma forma, se podría entender a la religión, las actividades festivas, las actividades propias de la iglesia y su volumetría como arquitectura del lugar.

- El 76,5 \% de la población encuestada considera que la apropiación social-urbana es una de las potencialidades de la iglesia de Huamán que la convierten en un elemento estructurador del fortalecimiento de la identidad local del distrito de Víctor Larco. Esta constituye una potencialidad puesto que la sociedad lo ha convertido en suyo, apropiándose de las actividades, muebles e inmuebles, según normas internacionales. Las actividades que se realizan a su alrededor, como las fiestas patronales, concentran gran cantidad de público sobre este volumen y su contexto inmediato. Esto muestra una significativa apropiación social-urbana del contexto inmediato a la iglesia como monumento y como hecho religioso. 
- El 79,6 \% de la población encuestada considera que el valor monumental es una de las potencialidades de la iglesia de Huamán que la convierte en un elemento estructurador del fortalecimiento de la identidad local del distrito de Víctor Larco. El valor monumental es una potencialidad porque forma parte de la historia del pueblo de Huamán, su historia es sinónimo de identidad y localidad porque es parte de este. El bien inmueble está considerado por la región y por la nación como una edificación con valor monumental según decreto supremo. Asimismo, el valor monumental es una forma de rescatar la historia y por consecuencia la identidad de un espacio que muestra connotaciones histórico-monumentales.

- El 90,3\% de la población encuestada considera que la actividad religiosa-cultural es una de las potencialidades de la iglesia de Huamán que la convierte en un elemento estructurador del fortalecimiento de la identidad local del distrito de Víctor Larco. Se constituye en parte de la formación religiosa del pueblo de Huamán. Esta actividad permite reunir gran cantidad de personas que hacen uso de ese espacio público, juntándose en el actividades, religiosas, culturales y comerciales. Además, las actividades religiosas y culturales son las que dan vida al monumento y sus contextos.

\section{Referencias}

Arroyo, M. (2001). Base de capital de transición de «campamento minero» a «ciudad sustentable». Revista Ambiente y Desarrollo, 17(3), 31-37.

Camarena, M. y Tunal, G. (2009). La religión como una dimensión de la cultura. Nómadas. Revista Crítica de Ciencias Sociales y Jurídicas, 22(2), 1-15.

Christian, W. (1978). Religiosidad popular. Estudio antropológico en un valle español. Madrid: Tecnos.

Connor, D. (1997). Participación pública: un manual. Cómo prevenir y resolver los conflictos públicos. Victoria, British Columbia, Canadá: Development Press.

Correa, J. (2005). Las iglesias en los pueblos de indios del valle de Moche. Revista Waka XXI(3), 83-133.

Durkheim, E. (1967). Sociologie et philosophie. París: Presses Universitaires de France.

Durkheim, E. (1982). Las formas elementales de la vida religiosa. Madrid: Akal.

Fonseca, C. (2005). Territorios e imaginarios entre lugares urbanos: procesos de identidad y región en ciudades de los Andes. Manizales: Editorial Universidad de Caldas.

García, N (1999). Los usos sociales del Patrimonio Cultural En E. Aguilar (Coord.), Patrimonio Etnológico. Nuevas perspectivas de estudio (pp. 16-33). España: Junta de Andalucía, Instituto Andaluz del Patrimonio Histórico

Gómez, L. (2009). Documentos internacionales de conservación y restauración. México D. F.: Instituto Nacional de Antropología e Historia (INAH) y Consejo Nacional para la Cultura y las Artes (Conaculta).

Marcos, J. (2005). La tradición, el patrimonio y la identidad. Badajoz: Universidad de Extremadura.

Mesa, J. (2011). El Barroco Mestizo en la Costa del Perú: La Iglesia de Santiago de Huamán en Trujillo. España: GRISO-Universidad de Navarra/Fundación Visión Cultural.

Muñoz, A. (2010). Arquitectura y Memoria. El Patrimonio Arquitectónico y la Ley de Memoria Histórica. Escuela de Arquitectura de Madrid.

Pérez-Agote, A. (2016). La religión como identidad colectiva: las relaciones sociológicas entre religión e identidad. Papeles del CEIC, International Journal on Collective Identity Research, (2).

Prat i Carós, J. (1989). Los santuarios marianos en Cataluña: una aproximación desde la etnografía. En C. Álvarez et. al. (Coords.), La religiosidad popular II Vida y muerte: la imaginación religiosa (pp. 211-252). Barcelona: Anthropos.

Prats, L. (2004). Antropología y Patrimonio. Barcelona: Ariel Patrimonio.

Pujadas, J. (1993). Etnicidad. Identidad cultural de los pueblos. Salamanca: Eudema. 
devenir Vol.6, N¹2, JULIO-DICIEMBRE 2019, PP. 137-154 - EstudIOS I ISSN 2312-7562 | E-ISSN 2616-4949 UnIVERSIDAD NACIONAL DE INGENIERÍA, LIMA

doi: https://doi.org/10.21754/devenir.v6i12.747

Ruíz, A. (2001). Quinta conferencia interparlamentaria de minería y energía para América Latina (CIME, 2001). Serie Seminarios y Conferencias, LC/L.1642-P, Comisión Económica para América Latina y el Caribe. Santiago de Chile: Naciones Unidas.

Seguel, R., Benavente, A. y Ossa, C. (2010). Restauración de imágenes de culto: propuesta teórica metodológica para la intervención de objetos de devoción. Revista Conserva, (47), 47-65.

Tilly, C. (1990). Coercion, Capital, and European States, AD 990-1990. Cambridge, Mass., EE. UU.: B. Blackwell.

Vega, M. (2009). Historia Documental de Trujillo del Perú. Blogspot. Recuperado de http://historiadocumentaldetrujillodelperu.blogspot.com/2009/02/un-documento-del-siglo-xvii-parala.htmlw 